\title{
Research on Depth Development of the Cultivated Land Resources and the Sustainable Development of Agriculture
}

\author{
Qi Meng ${ }^{1, a}$ \\ ${ }^{1}$ Sichuan Agricultural University, College of Literature and Law, Department of Law, Yaan, Sichuan, \\ China, 625014 \\ aemail,
}

Keywords: Depth Development, Cultivated Land Resources, Sustainable Development, Agriculture

\begin{abstract}
Due to human and natural factors, not only the number of arable land is reducing, but also the quality failures. In order to achieve sustainable development of agriculture, we must take the road of industrialization and technically to the progressive realization of "bio-engineering" technology. China's specific national conditions of China's agriculture can not take resources into the expansion of the extension type of the road, but only connotative conservation and protection of resources, improve their road utilization and output rate. Therefore, China's sustainable development of agriculture must be to conserve and protect the resource-intensive growth pattern from extensive mode of growth and wasteful destruction of resources.
\end{abstract}

\section{Introduction}

Because weaken the increase of China's grain production capacity and demand, by 2030, China's grain shortfall will increase tons of grain imports will account for $56 \%$ of total consumption of grain per year. Therefore, any country can fill such a huge shortfall of grain to China. Although Brown's view was refuted by Chinese scholars and some foreign experts, but its "alarmist" but it can cause us to focus on agriculture. Inseparable arable land for food production, agricultural production arable land is irreplaceable means of production, and it is a non-renewable resource. To this end, Comrade pointed out: "protection of arable land is to protect our lifeline." We must resolutely implement the party's fourth Session of the Fifth Plenary Session "suggestions" "to strengthen agricultural development on the top of the national economy, it is necessary from the current situation of cultivated land in China proceed.

\section{The Status and the Crisis of Cultivated Land in China}

Per Capita Arable Land Is Limited. China's land area of 9.6 million square kilometers, about 144 million hectares, about 20 million mu of arable land available, but only 1166 acres of arable land per capita, well below the world average (4117 acres), even lower than Canada (26 acres), United States ( 11143 acres), even lower than India (2197 acres), and that China has 666 counties 018 acres of arable land per capita is lower than the warning line FAO identified, of which 015 acres is less than 463 counties, accounting for county (district 2317\%) of the total. More seriously, with the growing population, the per capita arable land is declining. According to statistics, 1986) a net decrease of 2899 acres of arable land in 1995, an average annual reduction of arable land 290 acres, if this trend continues, then our country in 2050 may not be arable.

The Overall Level of Farmland Quality Is Low. The larger of arable land, poor quality, low-volume ratio. Arable land in the country, located in the mountains, hills, plateau region accounted for $60 \%$ of the distribution in the plains and basins accounted for only $34 \%$. Yangtze River and its south region, water accounted for $81 \%$ of the national total, but only $36 \%$ of the country's arable land; $19 \%$ of the Huaihe River and north of the region, only the total amount of water resources, and the country's arable land accounts $64 \% .39 \%$ of the country has to protect water resources (including irrigation) of the total arable land only. There are 9100 acres (account for $4510 \%$ of the national total arable land) cultivated land slope greater than 25 degrees, serious soil 
erosion. Calculated according to the current grain output per mu more than 400 kilograms of high-yielding arable land accounted for only 1618\%, $200 \mathrm{~kg}$ per mu of low-yield farmland accounted for $4715 \%$ per mu 200) 400 kilograms middle field accounted for 3517 percent, the proportion of low-yielding farmland up to $8312 \%$.

Severe Degradation of Arable Land. Because affected by desertification, China's arid and semi-arid areas of arable land, $40 \%$ have different degrees of degradation. About $30 \%$ of the arable land of the country suffer from soil erosion to varying degrees. According to the results of satellite remote sensing survey, China's current total soil erosion area of 3.67 million square kilometers, accounting for $3812 \%$ of land area. Desertification area also showed a growing trend. From the late 1950 s to the 1970s, China's desertification land average annual expansion of 1500 square kilometers, with an average expansion of 2460 square kilometers per year since the 1980s. Currently, the desertification in northern China 200,000 square kilometers of land area, the potential desertification land area and 16 million square kilometers. In addition, the widespread presence of salt fields, land pollution also makes our arable land degradation, the quality is still declining, while the number of arable land continued to decline.

A Significant Reduction of Arable Land. According to statistics, in 1985-1995 decade, a net decrease of 2899 acres of arable land, an average reduction of 290 acres per year. The loss of arable land, in addition to the inevitable natural variations and rational urbanization and other factors, human error is one of the main reasons. A Case Study of Development Zones in previous years, the first should be sure that this is our country industrialization and the inevitable process of economic growth and structural adjustment of our economy, as well as China's economic integration with the world economy, we have made important contribution, but also the emergence of new problems and new contradictions, in which the cost of the loss of arable land too much, leased land idle, abandoned, and the land has been developed rational and efficient use of the most prominent issues. For the establishment of development zones, land is too large, covers an area of 2400 acres, but mostly arable land, especially in the suburbs of good farmland.

\section{Reasons of Reduction of Arable Land in China}

The Rapid Growth of Non-Agricultural Construction Land. At present there are some outstanding problems in arable land use and management, resulting in excessive growth of non-agricultural land for construction. 1 . With the same time the industrial economy and population growth, the construction scale, accelerating urbanization, factories, housing, roads, etc. take up a lot of arable land, it is difficult to avoid. But striking is the real estate development in recent years, heat and hot zone, so that our Cultivated slashed. Meanwhile, some alarming rate of expansion of the town, established more than 40 years, the town has expanded some 4-6 times. There are some places wind blowing landscape and build an upscale luxury establishments, the waste of land has reached alarming proportions. 2. some places illegal Random occupation of farmland more serious problem of illegal approval, the phenomenon of illegal land use repeated.

Serious Soil Erosion, Degradation of Land Ecological Environment, Reduction of Arable Land. 1. serious soil erosion in China. Because of the high terrain, gravity gradient, coupled with the pressure of population growth and economic development of ultra-high speed, there has been plowed erodible land, deforestation, overgrazing and other phenomena that destroy the ecological, serious soil erosion, exacerbated by natural disasters. At present, China soil erosion area of 1.16 million square kilometers from the early liberation, expanded to 1.5 million square kilometers, accounting for about one-seventh of the total land, the loss of topsoil 5 billion tons per year, equivalent to $1 \mathrm{~cm}$ thick scrape arable land fertile soil, for the loss of nitrogen, phosphorus and potassium nutrients of about 40 million tons, equivalent to yield 100400,000 tons of fertilizer plant. The year 2000, China's top topsoil erosion will increase by 20-25\%, arable land productivity will be greatly decreased. 2. Desert swallowing our existing arable land. In the absence of a strong biological and engineering measures, the national desertification land from the original 137,000 square kilometers, increased to 176,000 square kilometers, and is still at a rate of 1560 square kilometers per year extensions. 
Insufficient Investment and Arable Land Pollution. As mentioned above, soil erosion, making farmland nitrogen, phosphorus and potassium nutrients also will be the loss of quality of cultivated land decreased. Meanwhile, the lack of investment in agriculture to make farmland nutrients are not replenish. The proportion of state investment in agriculture declined. After the founding of the proportion of investment in agriculture has been declining. From 10.5\% "Fifth" period, down 3.36\% to the "Plan" period, from 6.21\% in 1984 down to 2.6\% in 1994, the beginning of 1995 has dropped to 1.7\%. Agricultural financial expenditure total state expenditure has dropped, the government allocates funds for supporting agriculture, the "Plan" period of 65 billion yuan, accounting for $10 \%$ of the country's total fiscal expenditure, "Plan" period dropped to $8.4 \%$. Agricultural Credit cent of the national total proportion of credit also declined. Besides, since the entire national economy especially industrial excessive growth (this growth was mainly driven by investment) and unbalanced market process, so that the already weak attraction of funds into agriculture more difficult situation, who do not want to take the initiative to increase investment in agriculture, agricultural inputs, the situation is not optimistic.

\section{The Depth Development of Cultivated Land Resources is the Only Way of Sustainable Development of Agriculture}

Sustainable development of economy and society, based on sustainable development of agriculture-based, and sustainable development of agriculture requires a certain area (number) and a certain quality of arable land as a guarantee. Since 1996, countries have developed to ensure the dynamic balance of total farmland, major policies to achieve sustainable development of agriculture. This is made from cultivated area (number) on a certain degree of protection, but the realization of sustainable development of agriculture is an important part of the quality and quantity of food production, which in turn is based on the appropriate quantity and quality of cultivated land as a guarantee. Different area of arable land with different quality, output rates are different, the significance of sustainable development of agriculture is not the same. Compared with advanced countries, China's per capita arable land serious lack of resources, reserve land resources are very limited, which determines the type of extension can not go into the expansion of cultivated land resources, but only connotative conservation and protection of existing arable land resources, improve the efficiency and productivity of the road, which is a land-based resources in the depth of the development of the road. Sustainable development of our agriculture, we must turn to conservation and protection of farmland resources intensive growth mode from the waste and destruction of the extensive growth mode farmland.

\section{The Implementation Direction and Ways of China's Arable Land Resource'S Depth Development and Agricultural Sustainable Development}

Achieve sustainable agricultural development in the most important prerequisite is to ensure the quantity and quality of arable land. Arable agricultural production is the most basic means of production, all agricultural and forestry crops must be grown on the land. Contradictions of the quality and quantity of food production and the growing demand for more and more prominent. Therefore, if you simply focus on the depth of the development of arable farmland to the neglect of quantity and quality assurance problems, then the result would be wasted, more harm than good, it is impossible to achieve sustainable development of agriculture. Since 1996, the state and all levels of government on the number of arable land protection issues growing importance and quality assurance issues are rarely cultivated land involved, in fact, both are equally important need to protect national policies and laws.

The government's macro-control policies and regulations in agriculture, should be conducive to the sustainable utilization of cultivated land resources and sustainable agricultural development. Agriculture is the foundation of the national economy, is the main body of the rural community, agriculture and sustainable rural development is to achieve sustainable development of our core strategy. At present, China has a population of more than $70 \%$ retention in the countryside, in the 
relatively homogeneous agricultural production on limited land, slow farmers income growth, a serious shortage of investment in agriculture, rural infrastructure and agricultural production conditions behind the low level of production technology, low productivity, decline in agricultural comparative advantage, the gap between workers and peasants, urban-rural gap is widening, which is restricting agricultural sustainable development of the underlying causes.

Relying on scientific and technological progress, increase the contribution of science and technology in the share of agricultural growth in the sustainable development of agriculture. At present, China's contribution to agricultural growth in the share of only $35 \%$ of science and technology, and agriculture in developed countries has reached more than $60 \%$, speed up China's agricultural science and technology has become essential. Use of biological engineering technology to promote agricultural growth, mainly to do the following aspects: (1) promote the "seeds of revolution", the implementation of seed industrialization projects; (2) to accelerate existing agricultural scientific and technological achievements to promote the application; (3) improve farmers, especially young farmers qualities. Finally, it must be noted that the use of biological engineering technology needs a certain quality and quantity of arable land to ensure that as a basis.

It is the right way to develop ecological agriculture and sustainable use of agricultural sustainable development of cultivated land resources. From the point of view of reproduction characteristics of agricultural and non-agricultural production process is different productive sectors, agriculture is the production process of living matter, it is not only involved in the biosphere biogeochemical cycles, but also directly involved in the ecological cycle of the ecosystem. Forming nutrient cycling ecosystem. Therefore, we can say, is a typical agriculture eco - economic system. This determines that people pay attention to agricultural production in economic law at the same time, we must not ignore the laws of ecology. Otherwise, it will be punished, not only in agricultural production can not achieve the desired output and efficiency, but also ultimately undermine future sustainable development of agriculture.

\section{Conclusion}

The prominent contradiction of China's agriculture is population explosion and farmland dropped. Bio-engineering technology to solve our agricultural resources are scarce, especially the shortage of arable land, providing a unique opportunity. Because this technology does not depend on physical strength, but in the people-centered competition; traditional biotechnology, organic agriculture has been inherited in our process of agricultural production; China has a number of technology professionals in biotechnology. Bio-engineering technology to become the dominant technology in agriculture requires a process, in the meantime, we should be based on current situation of cultivated land resources, agricultural technology to maximize the use of the recent economic, ecological and economic benefits and long-term economic benefits of the combination of technology, to obtain better economic and social benefits.

\section{References}

[1] Jia Xinzhang, Li Jingyuan. Chinese Rural Economy, Vol. 6 (20104) No 53, p.25-26

[2] Peng Sue, Wang Yunhui, Wang Qunyong. Economic Research, Vol. 12 (2015) No 27, p.74-76

[3] Qian Xiyuan, Jing Jianfen, Hou XuSiem. Economic System, Vol. 30 (2014) No 19, p.144-145

[4] Wang Kuailiang. Contemporary Finance, Vol. 29 (2011) No 27, p.21-23

[5] Zhang Gongxu, Sun Jing. Zhongnan University of Finance and Economics, Vol. 8 (2013) No 27, p.57-60 